\title{
INTERAÇÃO QUÍMICA DA FRAÇÃO FIBRA E BIOATIVOS COM AÇÃO ANTIOXIDANTE: ANÁLISE DE MIX DE RESÍDUO DE FRUTAS E VEGETAIS APÓS TRATAMENTO ENZIMÁTICO
}

\author{
$\underline{\text { Mariana Pumar Seljan }}^{1}$; Roberta Melquiades Silva de Andrade ${ }^{2,4}$; Matheus Ajckson Barros \\ Lima $^{1}$; Fernanda do Carmo da Silva ${ }^{3}$; Nathania de Sá Mendes ${ }^{1}$; Édira Castello Branco de \\ Andrade Gonçalves ${ }^{1}{ }^{2}$ (ediracba.analisedealimentos@unirio.br)
}

1. Escola de Nutrição - Universidade Federal do Estado do Rio de Janeiro (UNIRIO)

2. Programa de Pós-graduação em Alimentos e Nutrição (PPGAN) - Universidade Federal do Estado do Rio de Janeiro (UNIRIO)

3. Instituto de Biociências - Universidade Federal do Estado do Rio de Janeiro (UNIRIO)

4. Universidade Federal do Rio de Janeiro (UFRJ)- Campus UFRJ Macaé

Os subprodutos obtidos a partir do processamento de frutas e vegetais estão ganhando atenção por representarem uma nova e econômica fonte de ingredientes funcionais, como fibras alimentares e compostos fenólicos. Os benefícios fisiológicos das fibras alimentares, no entanto, dependem da quantidade ingerida, da composição e estrutura organizacional, características físico-químicas e da associação com compostos fenólicos. Do mesmo modo, os efeitos benéficos à saúde promovidos por compostos fenólicos dependem da quantidade ingerida além de sua bioacessibilidade, que pode ser afetada por diferentes fatores, dentre eles, as associações na matriz alimentícia, especialmente à fração fibra alimentar. Neste sentido, parece relevante realizar a separação desses compostos com modificação na estrutura da fração fibra insolúvel, pois pode promover maior liberação de compostos fenólicos da matriz e, consequentemente, aumento da atividade antioxidante, sem alterar o teor de fibra alimentar total, modificando apenas a proporção das frações fibra alimentar solúvel e insolúvel no alimento. Assim, o presente trabalho teve por objetivo aplicar tratamento enzimático em mix de resíduos de frutas e hortaliças visando aumento da bioacessibilidade de compostos fenólicos com redução do teor de fibra alimentar insolúvel. A matéria-prima utilizada foi mix de resíduos de frutas e hortaliças, na forma de farinha, elaborado a partir de resíduos do processamento de bebida funcional. Um delineamento composto central associado a metodologia de Superfície de Resposta foi proposto com dez experimentos para avaliar a influência dos parâmetros de concentração da enzima (Viscozyme) (15, 30 e $45 \mathrm{FBG})$ e temperatura $\left(30^{\circ} \mathrm{C}, 45^{\circ} \mathrm{C}\right.$ e $\left.60^{\circ} \mathrm{C}\right)$ sobre o teor de fibras insolúveis e aumento da atividade antioxidante (variável de resposta) e determinar os parâmetros relevantes neste processo. Os experimentos foram realizados a partir de soluções aquosas do mix de resíduos colocadas em banho maria com agitação (200rpm), durante 30 minutos, nas condições de concentração de enzima e temperatura citadas previamente. Após o tratamento enzimático, as amostras foram secas em estufa a $105^{\circ} \mathrm{C}$ e foram feitas as análises; atividade antioxidante através do método de redução do radical DPPH e o teor de fibra alimentar insolúvel determinado pelo método enzimático-gravimétrico. Os parâmetros investigados apresentaram influência sobre o teor de fibra insolúvel da FFH e, através do gráfico de superfície de resposta, foi possível observar que a redução significativa do teor de fibra insolúvel, aproximadamente $18 \%$ de redução, ocorreu com níveis menores de temperatura $\left(30\right.$ a $\left.35^{\circ} \mathrm{C}\right)$ e concentração intermediária da enzima Viscozyme (25 a 35 FBG). Ao utilizar a atividade antioxidante como variável de resposta, foi verificado um aumento de aproximadamente $5 \%$ da atividade antioxidante das amostras com o aumento sensível da temperatura (toda a faixa entre 30 a $60^{\circ} \mathrm{C}$ ) e da concentração da Viscozyme (40 a 45 FBG). Em função da interação desses compostos na matriz alimentícia, sugere-se que o aumento da atividade antioxidante da amostra observado esteja relacionado a possível modificação na estrutura da fração fibra insolúvel provocado pelo tratamento enzimático, com maior liberação de compostos fenólicos, sem alterar o teor de fibra alimentar total, modificando apenas a proporção das frações fibra alimentar solúvel e insolúvel da matriz, com redução da fração insolúvel. Com isso, estudos de bioacessibilidade dos compostos fenólicos e avaliação do perfil dos mesmos devem ser realizados para melhor avaliação da interação destes na matriz estudada.

Palavras-chave: mix de resíduos; tratamento enzimático; fibra alimentar; compostos fenólicos 